\title{
Chronic Stress Down-Regulates Growth Hormone Gene Expression in Peripheral Blood Mononuclear Cells of Older Adults
}

\author{
William B. Malarkey, ${ }^{1,4,5}$ Hong Wu, John T. Cacioppo, ${ }^{2}$ Kevin L. Malarkey, \\ Kirsten M. Poehlmann, ${ }^{2}$ Ronald Glaser, ${ }^{1,4,5}$ and Janice K. Kiecolt-Glaser ${ }^{2,3}$ \\ The Ohio State University Medical Center: Departments of 'Internal Medicine, ${ }^{2} P$ sychology, ${ }^{3} P$ sychiatry, \\ ${ }^{4} \mathrm{Medical}$ Microbiology and Immunology, and ${ }^{5} \mathrm{OSU}$ Comprehensive Cancer Center, ${ }^{5} \mathrm{Columbus,} \mathrm{OH}$
}

"Pituitary" peptides are produced in both endocrine and immune cells. Acute and chronic stress can alter pituitary peptide secretion and might also influence neuroendocrine gene expression in human immune cells. We reasoned that, in Alzheimer caregivers, the chronic stress of caregiving would impact on the sympathetic-adrenal-medullary and hypothalamicpituitary-adrenal axis possibly leading to alterations in GH mRNA in their peripheral blood mononuclear cells (PBMCs). Therefore, we evaluated 10 caregivers and 10 control subjects using a math and speech stress protocol to determine their neuroendocrine profile and to evaluate any relationship with mononuclear cell $\mathrm{GH}$ mRNA levels simultaneously acquired and then evaluated by a quantitative competitive RT-PCR technique. We found a significant $(p<.0001)$ decrease $50 \%$ in $\mathrm{GH}$ mRNA levels in cells from caregivers. Plasma ACTH and norepinephrine levels were negatively correlated with GH mRNA levels, suggesting their possible role in the down-regulation of mononuclear cell $\mathrm{GH}$ gene expression. These observations support the hypothesis that experiences associated with caregiving alter the brain's autonomic nervous system and neuroendocrine control of the hypothalamic-pituitary axis. These and perhaps other influences may then produce altered $\mathrm{GH}$ gene expression in mononuclear cells of chronically stressed individuals. It is tempting to speculate that the decreased GH mRNA that we found in these chronically stressed caregivers was partially responsible for their poor response to influenza vaccine and their delayed wound healing.

Received March 18, 1996; Revised May 2, 1996; Accepted May 7, 1996. Author to whom all correspondence and reprint requests should be addressed: William B. Malarkey, N-1105 DoanHall, 410 West Tenth Avenue, Columbus,Ohio 43210.E-Mail: Malarkey\%crcvax.decnet@gate.hosp.ohiostate.edu
Key Words: Stress; GH mRNA; ACTH; endocrineimmune; caregiving.

\section{Introduction}

It has become increasingly clear that the endocrine and immune systems have bidirectional effects at several levels such that "pituitary" hormones produced in the pituitary or in lymphocytes can influence immune function (Ader et al., 1990; Weigent and Blalock, 1990). For example, peripheral blood mononuclear cells (PBMCs) can secrete growth hormone (GH) and prolactin (Weigent and Blalock, 1990; Sabharwal et al., 1992a; Varma et al., 1993; Hattori et al., 1994) and GH mRNA and PRL mRNA can be localized in each tissue of the human immune system (Wu et al., 1995; Wu et al., 1996).

Acute stress can alter cellular immune function in humans by a direct effect on immune cells, by neurogenic input to immune organs, and by alterations in lymphocyte trafficking modulated by stress hormones (Ader et al., 1990). Therefore, chronic stress might extend this influence to include neuroendocrine change within the lymphocyte. For several yr, our group has been evaluating the endocrine, immune, and cardiovascular effects of long-term caregiving stress. The stress and social isolation that characterizes caregivers of patients with Alzheimer's has been associated with higher blood pressure, a decrease in cellular immune function, and depression (Kiecolt-Glaser et al., 1990).

We reasoned that, in Alzheimer caregivers, the chronic stress of social isolation (Berkman, 1995) would impact on the sympathetic-adrenal-medullary (SAM) and hypothalamic-pituitary-adrenal (HPA) axis, possibly leading to alterations in GH mRNA in their PBMCs. Therefore, we evaluated 10 caregivers and 10 control subjects using a math and speech stress protocol to determine their neuroendocrine reactivity and to evaluate any relationship with $\mathrm{GH}$ mRNA levels simultaneously acquired and then evaluated by a quantitative competitive reverse-transciption polymerase chain reaction (RT-PCR) technique. 


\section{Material and Methods}

\section{Subjects}

Ten elderly female caregivers who suffered from the chronic stress of caring for a spouse with Alzheimer's disease and 10 age- and sex-matched control women were evaluated. Their average age was $69 \mathrm{yr}$. We also evaluated a third group $(n=6)$ from whom we only drew a fasting blood sample to control for the possible effect of the acute stressor on GH mRNA levels, as we had to pool the pre- and poststress samples in order to obtain enough cells for assay. For inclusion in the study, subjects had to be in good health, body mass index $<31$, and normotensive; had no history of a chronic illness; were postmenopausal and not on estrogen replacement; were not on any medicine or tobacco products; and were asked not to ingest any medications or alcohol $24 \mathrm{~h}$ preceding the test day.

\section{Protocol}

We used a brief laboratory stress protocol that has produced significant elevations in catecholamine levels and autonomic responses in young and elderly individuals (Sgoutas-Emch et al., 1994; Cacioppo et al., 1995). This stress protocol was employed to determine if the endocrine changes (e.g., reactivity in the SAM and HPA axis) to these stressors was correlated with group differences in GH mRNA expression in the PBMCs. All subjects were evaluated beginning at $0900 \mathrm{~h}$ when electrodes and a blood pressure cuff were positioned for cardiovascular measurements and an indwelling needle was inserted for blood sampling. Approximately $1 \mathrm{~h}$ later, subjects were seated in an upright position and instructed to relax for $5 \mathrm{~min}$ while basal blood pressure was measured manually. Impedance and electrocardiographic measurements were recorded. Following these baseline measures, subjects received instructions for a 6-min speech task and a 6-min mental arithmetic task (SgoutasEmch et al., 1994; Cacioppo et al., 1995). The second stressor immediately followed completion of the first, and the order of these stressors was counterbalanced across subjects. BP and blood samples were collected from baseline, after each stressor and $30 \mathrm{~min}$ into the recovery period.

The speech stressor we used is a variation of one previously described (Sgoutas-Emch et al., 1994; Cacioppo et al., 1995). Subjects were asked to imagine that they were being harassed by an obnoxious bill collector who insisted they had not paid a large medical bill that they had in fact paid. Participants were instructed to prepare a 3-min speech that they would deliver to the bill collector's supervisor, including the following issues: tell their side of the story, tell the supervisor what the bill collector did wrong and why the bill collector may have suspected them of not paying the bill, say how they can prove they did pay the bill, tell what should happen to the bill collector for the mistake, and summarize their points. Subjects were instructed to give intelligent and wellthoughtout answers because their speech would be recorded and compared with the speeches of others. Subjects were given $3 \mathrm{~min}$ to prepare and $3 \mathrm{~min}$ to present their speeches.

Subjects performed six one-minute serial subtraction problems continuously for $6 \mathrm{~min}$ (Wang et al., 1995). Subjects were instructed that any error they made would be corrected by the experimenter, and that they should continue from the correct number. To maintain maximal task involvement and moderate task difficulty, the minuend and subtrahend for each min were set so that the subject would complete approx 10 serial subtractions per minute. Cardiovascular measurements were recorded throughout the 12-min stress period.

Assays

Epinephrine (EPI), norepinephrine (NEPI), ACTH, and cortisol were performed from blood samples acquired at baseline, after the first stressor (i.e., $6 \mathrm{~min}$ after the onset of the stressor), and after the second of the two stressors (i.e., $12 \mathrm{~min}$ after the onset of the stress protocol). Plasma ACTH levels were assayed with a immunoradiometric assay supplied by Nichols Institute (San Juan Capistrano, CA) and plasma cortisol levels were assayed with a fluorescent polarization technique (TDX-Abbott Laboratories, Chicago, IL). Both assays have an intra- and interassay coefficient of variation (CV) of $<10 \%$. GH was measured by a sensitive chemiluminescence technique (Nichols Institute, San Juan Capistrano, CA) with intra- and intercoefficients of variation less than $8 \%$. Plasma catecholamine concentrations (EPI and NEPI) levels were determined by highperformance liquid chromatography (HPLC) with a Waters system(Millipore, Waters Division, Marlborough, MA) with an electrochemical detector. The sensitivity of this HPLC system for EPI is $10 \mathrm{pg} / \mathrm{mL}$ and for NEPI, is $20 \mathrm{pg} / \mathrm{mL}$. This assay has an interassay CV for EPI of $15 \%$ and for NEPI of $9 \%$. Dehyroepiandrosterone sulfate (DHEAS) and insulin growth factor-I(IGF-1) were measured by radioimmunoassay (Diagnostic Systems Laboratories, Webster, TX and Nichols Institute) and have an intra- and interassay CV of $<8 \%$.

\section{Competitive RT-PCR}

\section{RNA Extraction}

Total RNA was obtained from Ficoll/Hypaque (Sigma, St. Louis, MO) separated human PBMCs following two phenol-chloroform-isoamyl alcohol extractions to increase RNA purity. RNA integrity was verified on agarose gels with ethidium bromide staining and was quantified using a spectrophotometer at a dilution of 1:100.

\section{Reverse Transcription}

The reverse transcription (RT) from RNA to cDNA was performed in a total volume of $25 \mu \mathrm{L}$ containing $5 \mu \mathrm{g}$ total RNA, $1 \mu \mathrm{L}$ random primer $(90 \mathrm{U} / \mathrm{mL}), 1 \mathrm{X}$ first strand buffer

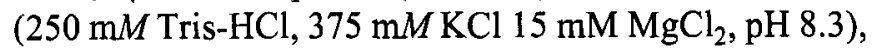
$200 \mu M$ of deoxynucleotide triphosphate, $0.5 \mu \mathrm{L}$ DTT $(0.1 M)$ and 1 U of RNase inhibitor. For comparisons of mRNA levels among different RNA samples, RT was performed simultaneously using reagents from a single master mix. 


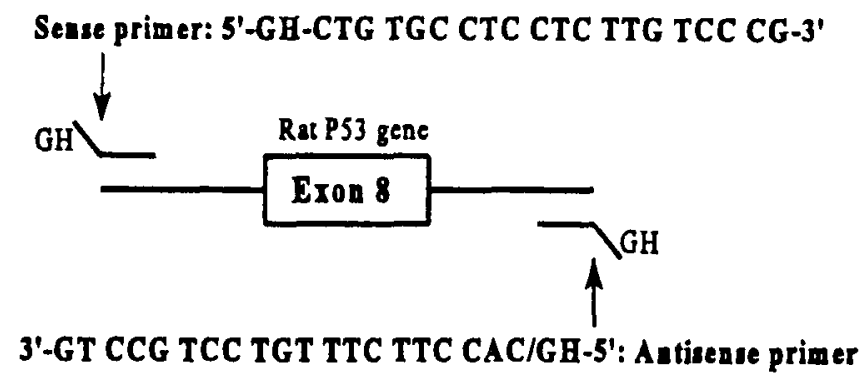

Fig. 1. Diagram of rat p53 gene fragment and hGH-rat p53 composite primers.

\section{Generation of Heterologous \\ Competitive Standard Fragment}

Composite primers were carefully designed and synthesized with the DNA model 391 synthesizer (Applied Biosystems, Foster city, CA) by using the solid-phase phosphoramidite method. Each composite primer has the hGHgene primer sequence attached to a short, 20-nucleotide stretch of sequence designed to hybridize to opposite strands of flanking regions of exon 8 of the rat $\mathrm{p} 53$ gene (Wong et al., 1995) (Fig. 1).

Genomic DNA, isolated from rat esophageal epithelial cells (Wang et al., 1995), was used as a template for PCR amplification with composite primers. This PCR amplification resulted in a fragment of $241 \mathrm{bp}$ with the $\mathrm{hGH}$ primer sites at the $5^{\prime}$ end of the sense and antisense strands of the fragments (Fig. 2). This competitive standard fragment differed by $80 \mathrm{bp}$ from the $161 \mathrm{bphGH}$ fragment amplified from cDNA derived from human PBMCs total RNA.

\section{Competitive PCR of $G H \mathrm{mRNA}$}

GH primers flanking exons 2, 3, and 4 in the human $\mathrm{GH}$ gene were synthesized (Wu et al., 1996). The sense primer ( 5 ' end) is located within the last 20 nucleotides of exon 2 and the first seven nucleotides of exon 3 of the human GH gene, while the antisense primer ( 3 ' end) is complementary to the last six and the first 21 nucleotides of exons 3 and 4 so that contamination by genomic DNA would be avoided (Wu et al., 1996). The amplified fragments were 161-bp in length. The sequence of the sense primer was 5'-ATG ACA CCT ATC AGG AGT TTG AAG AAG-3', and the antisense primer was 5'-GAT GCG GAG CAG CTC TAG GTT AGA TTT-3'.

A rat $\mathrm{p} 53$ gene fragment (241-bp) was chosen from many potential candidates for use as a competitive standard that was different in size from the target gene GH (161bp) PCR product. This competetive standard consists of a nonhomologous DNA fragment with primer templates that "mimic" and are thus, recognized by GH gene-specific primers (Figs. 1 and 2). To determine appropriate dilutions of competitve standard for competitive PCR, we did a preliminary titration experiment in which 10 twofold serial dilutions (from $1.25 \times 10^{-3}$ to $640 \times 10^{-3}$ attomoles) were emperically made and coamplified with a constant amount of sample cDNA. After acquiring this information we were able to reduce the number of serial dilutions to $\operatorname{six}(5 \times$

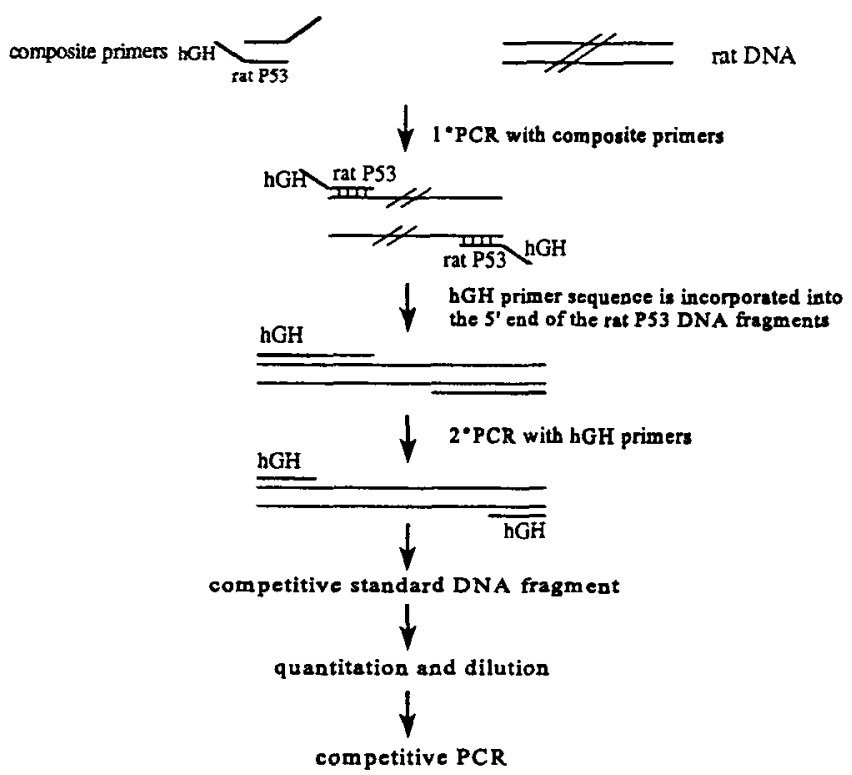

Fig. 2. Scheme for generating competitive standard. Competitive standards are generated by two successive PCR amplifications. In the first PCR reaction, a rat $\mathrm{pS} 3$ DNA fragment is amplified using the composite primers. During amplification, the GH-specific primer sequences are incorporated into the PCR products. This PCR product is diluted and used to perform a second PCR amplification with primers for the GH gene only. The GH second amplification utilized only the hGH primer sequence to ensure all 3 ' and 5 ' ends of rat $\mathrm{p} 53$ fragments contained the $\mathrm{GH}$ sequence.

$10^{-3}$ to $160 \times 10^{-3}$ attomoles), which allowed both competitive standard and target $\mathrm{GH}$ fragments to be amplified and visualized on an agarose/EtBr gel. When coamplifying known amounts of the competitive fragment template with an unknown amount of cDNA in a "same-tube" reaction, less competitive fragment will be amplified with increasing concentration of cDNA in the unknown sample. The amplification efficiency of the two templates would be very similar under our PCR conditions, because our competitive standard share the same primer-binding sequences as our target GH fragment, and both of them are of similar size (Wang et al., 1989; Seibert and Larrick, 1993). Thus, the competitive template served as an internal control for quantitative PCR to measure the relative amount of corresponding cDNA in the unknown sample.

Competitive PCR was performed in a total volume of $50 \mu \mathrm{L}$ as follows: The serial diluted competitive standard and $8 \mu \mathrm{L}$ of cDNA (equivalent to about $0.33 \mu \mathrm{g}$ of total RNA) was used with $2 \mu \mathrm{L}, 10 \mathrm{~m} M$ Tris- $\mathrm{HCl}, \mathrm{pH} 8.3,50 \mathrm{~m} M$ $\mathrm{KCl}, 1.5 \mathrm{mM} \mathrm{MgCl}_{2}, 25 \mathrm{pmol}$ of each primer, $200 \mathrm{mM}$ of each deoxynucleotide triphosphate (GIBCO/BRL, Gaithersburg, MD), and 2.5 U of Taq polymerase (PerkinElmer/Cetus). Amplification was carried out in an automated Perkin-Elmer/Cetus 9600 thermal cycler for 35 cycles of denaturation for $30 \mathrm{~s}$ at $94^{\circ} \mathrm{C}$, annealing for $30 \mathrm{~s}$ at $62^{\circ} \mathrm{C}$ and extension for $30 \mathrm{~s}$ at $72^{\circ} \mathrm{C}$. Initial denaturation 


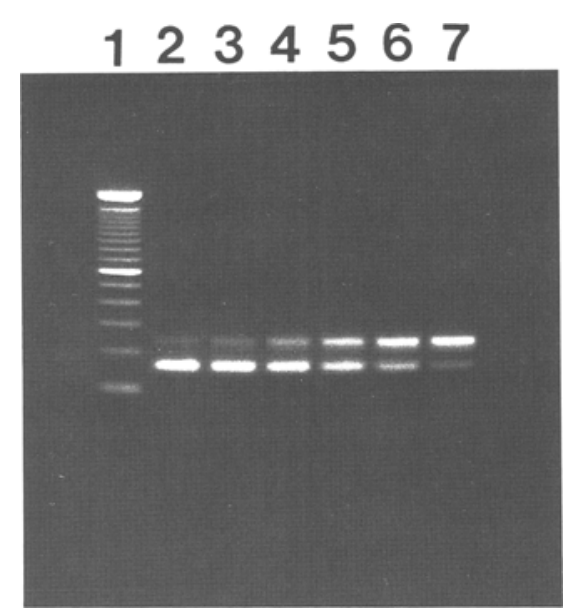

Fig. 3. Ethidium bromide stained $2 \%$ agarose gel showing quantitation of GH mRNA expression in human PBMCs by competitive RT-PCR. Dilutions of competitive standard $\left(5 \times 10^{-3}-160\right.$ $\times 10^{-3}$ attomoles/tube, the upper band from left to right, lane 2-lane 7) were added to a constant amount of mononuclear cell RNA $(0.33$ $\mu \mathrm{g} / \mathrm{tube}$, the lower band). The point at which the upper and lower bands are of equal intensity represents equal starting amounts. Lane $1=100 \mathrm{bp}$ DNA size marker.

was at $98^{\circ} \mathrm{C}$ for $8 \mathrm{~min}$ before the addition of Taq polymerase. To compare GH cDNA levels among three experimental groups, we performed simultaneous PCR amplification of samples from each group. One-fifth of the amplified product from these three samples was then examined on a single agarose/EtBr gel. A typical photograph of a competitive standard dilution series with one of the human PBMC RNA samples is shown in Fig. 3. A photographic negative was prepared and densitometry was carried out using a LKB laser densitometer (Pharmacia, Piscataway, NJ). Subsequently, the logarithm of the amount of amplified target $\mathrm{GH}$ and competitive standard was graphed as a function of the logarithm of the initial amount of standard (linear regression analysis). The initial equal amount of target GH cDNA in the reaction is extrapolated from the graph, based on the hypothesis that equal starting material could be assumed when the upper (competitive standard) and lower (GH cDNA fragment) bands were of equal intensity (once the band intensities were corrected for difference in fragment size) (Gilliland et al., 1990). Because the molar quantity of the competitive fragment was known, the actual number of unknown DNA molecules added to the PCR was determined. Thus, the number of GH mRNA molecules in the RNA sample could be calculated assuming that the efficiency of cDNA synthesis was 100\% (Gilliland et al., 1990; Siebert and Larrick, 1993). Difference of GH mRNA expression among the three experimental groups was analyzed using one-way analysis of variance (ANOVA).

At least two independent competitive RT-PCR studies were performed for each sample. Each of the independent experiments gave similar results. These data were analyzed using one-way ANOVA.

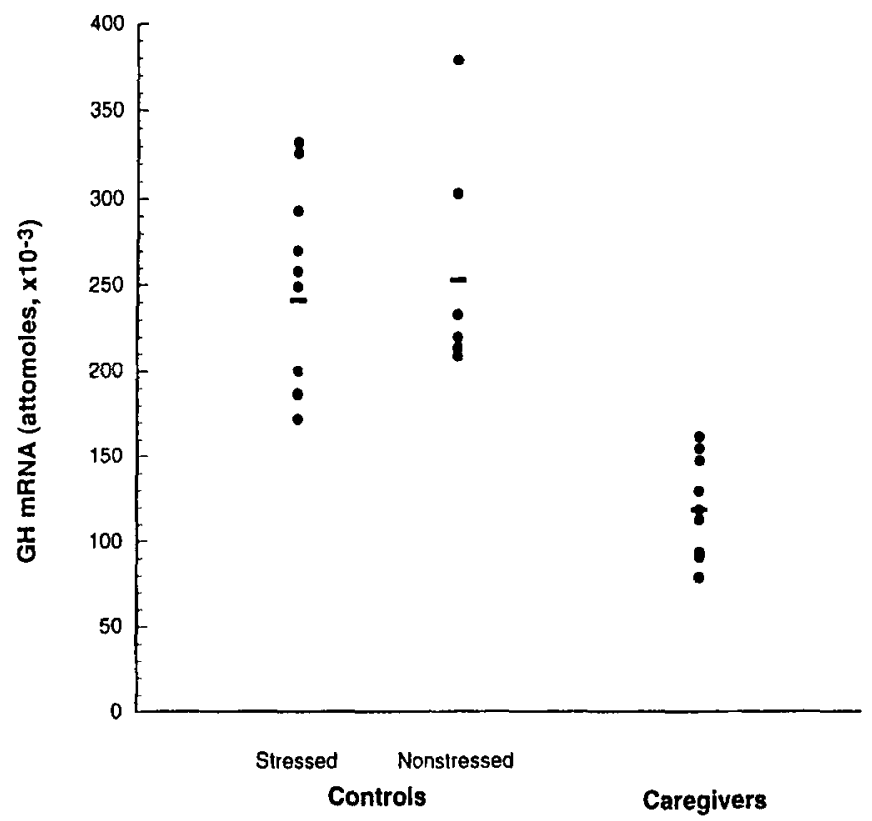

Fig. 4. Quantitative analysis of GH mRNA as measured by competitive RT-PCR after correcting for the difference in size between the competitive standard fragment and GH cDNA. We found $119 \pm 9 \times 10^{-3}$ attomoles (mean + SE) in the caregiver group, $241 \pm 18 \times 10^{-3}$ attomoles in the control group that received the stress protocol and $253 \pm 24 \times 10^{-3}$ attomoles in the nonstressed control group.

\section{Results}

\section{GH mRNA Levels in Three Elderly Female Populations}

Chronic stress-related changes of GH mRNA level in human PBMCs were measured using a quantitative competitive RT-PCR technique. The expression of GH mRNA from human PBMCs was 50\% less $(p<0.0001)$ in the caregiver group compared with that in the two control groups (Fig, 4). Also, there were no significant differences between the control women who had only basal samples drawn $(n=$ $6)$ and the control subjects $(n=10)$ who received the math and speech stressors $(p>0.69)$ (Fig. 4) where their basal and poststress blood samples had been pooled to provide enough cells for analysis.

\section{Cardiovascular-Endocrine Measures and Correlation with GH mRNA Levels}

Age, weight, systolic and diastolic blood pressure, heart rate, cortisol, DHEAS, NEPI, EPI, GH, IGF-1, were not different between caregivers and control women (Table 1). In contrast, baseline mean arterial pressure and $\mathrm{ACTH}$ levels were significantly $(p<.04, p<.01$, respectively) higher in the caregivers whereas parasympathetic tone (RSA, Table 2) was not different between the groups (Tables 1 and 2 ). The stressors produced appropriate increases in cardiovascular and endocrine variables, but there were no significant differences between the two groups regarding their poststressor levels (data not shown). In an attempt to determine which hormones of the HPA and SAM axis were 
Table 1

Baseline Endocrine Characteristics

\begin{tabular}{|c|c|c|c|c|c|c|c|c|c|}
\hline & Age & BMI & $\begin{array}{l}\text { ACTH, } \\
\mathrm{pmol} / \mathrm{L}\end{array}$ & $\begin{array}{c}\text { Cortisol, } \\
\mathrm{nmol} / \mathrm{L}\end{array}$ & $\begin{array}{c}\text { DHEAS, } \\
\mu \mathrm{mol} / \mathrm{L}\end{array}$ & $\begin{array}{c}\mathrm{NEPI} \\
\mathrm{nmol} / \mathrm{L}\end{array}$ & $\begin{array}{c}\text { EPI, } \\
\mathrm{pmol} / \mathrm{L}\end{array}$ & $\begin{array}{c}\mathrm{GH}, \\
\mu \mathrm{g} / \mathrm{L}\end{array}$ & IGF-1 \\
\hline Caregiver & $69.4 \pm 3.7$ & $22.8 \pm 2.7$ & $4.9^{a} \pm .9$ & $303.5 \pm 52.4$ & $2.0 \pm .5$ & $3.8 \pm .4$ & $154.5 \pm 34.9$ & $0.5 \pm .2$ & $125 \pm 4.9$ \\
\hline Control & $68.7 \pm 2.6$ & $24.1 \pm 1.9$ & $2.4 \pm .4$ & $303.5 \pm 41.4$ & $1.3 \pm .3$ & $3.1 \pm .4$ & $120.6 \pm 15.3$ & $0.6 \pm .2$ & $136 \pm 4.1$ \\
\hline
\end{tabular}

Table 2

Baseline Cardiovascular Characteristics

\begin{tabular}{lrrrrrr}
\hline & H.R. & SBP & DBP & MAP & PEP $^{a}$ & RSA $^{b}$ \\
\hline Caregiver & $80 \pm 8$ & $152 \pm 9$ & $88 \pm 4$ & $109 \pm 5$ & $81 \pm 9$ & $5.3 \pm .7$ \\
$\mathrm{P}$ & $(0.06)$ & $(0.08)$ & $(0.06)$ & $(0.04)$ & $(0.12)$ & $(0.45)$ \\
Control & $68 \pm 2$ & $134 \pm 4$ & $75 \pm 5$ & $94 \pm 4$ & $97 \pm 10$ & $5.1 \pm .4$ \\
\hline \multicolumn{2}{c}{${ }^{a}$ ms $^{2}$. } \\
\multicolumn{1}{l}{${ }^{b} \mathrm{LN}$ (band variance). } & & & &
\end{tabular}

Table 3

Correlations of Neurohormones with GHmRNA

\begin{tabular}{lcccccccc}
\hline & ACTH & $P$ & NEPI & $P$ & Cortisol & $P$ & GH & $P$ \\
\hline Basal & -0.535 & $<0.03$ & -0.602 & $<0.01$ & -0.108 & $>0.68$ & -0.194 & $>0.49$ \\
Midstress & -0.613 & $<0.01$ & -0.566 & $<0.02$ & -0.228 & $>0.28$ & -0.115 & $>0.68$ \\
Poststress & -0.595 & $<0.01$ & -0.558 & $<0.02$ & -0.208 & $>0.44$ & -0.256 & $>0.36$ \\
Recovery & -0.479 & $<0.01$ & -0.512 & $<0.05$ & -0.047 & $>0.86$ & -0.385 & $>0.16$ \\
\hline
\end{tabular}

associated with the decreased GH mRNA levels, we evaluated correlations and found significant relationships between GH mRNA and plasma ACTH $(p<0.01-0.03)$ and NEPI $(p<0.01-0.05)$ levels at four different time points (Table 3).

\section{Discussion}

In this study we noted an impressive decrease of $\mathrm{GH}$ mRNA in the PBMCs of chronically stressed caregivers compared to age- and weight-matched control groups. In fact, there was no overlap in GH mRNA levels between the control and caregiver populations. Since there was no difference in GH mRNA levels between the control groups (one received the stressors and the other control group had only a blood sample drawn), it suggested that chronic and not acute stress was responsible for the changes in the caregivers $\mathrm{GH}$ mRNA levels. Therefore, the social isolation and other factors that produce chronic stress in Alzheimer caregivers appears to be associated with decreasing $\mathrm{GH}$ gene expression in their PBMCs.

In order to examine possible neuroendocrine mechanism(s) that could explain these findings we evaluated hormones of the HPA and SMA axis, all of which have been shown to influence cellular immune function (Ader et al.,
1990). ACTH, cortisol, DHEAS, NEPI, and EPI were measured and only ACTH was found to be significantly different at baseline between the caregivers and controls. Next we evaluated the release of these hormones following math and speech stress. These laboratory stressors are similar to life event stress and hassles that are encountered daily. We found that the mean endocrine reactivity profile in the two groups was similar and, therefore, did not provide an explanation for the differences in GH mRNA.

The evaluation of a variety of cardiovascular variables did provide some insight into a factor that could have contributed to differences in GH mRNA levels between the two groups. At entry into the study, we noted higher heart rates, systolic and diastolic pressures, mean arterial blood pressure, and decreased preejection phase (PEP) of the cardiac cycle in the caregivers. Although only the mean arterial pressure was significantly different, these observations coupled with the absence of group differences in parasympathetic tone (RSA) suggest an enhanced CNS directed sympathetic activity in the caregivers.

Finally, we examined correlations between the GH mRNA concentrations and all the neuroendocrine variables obtained at baseline and during the stressors. We found that ACTH and NEPI at baseline and during stress were both 
significantly and negatively correlated with GH mRNA levels. The other neuroendocrines were not correlated with GH mRNA, including GH and IGF-1, suggesting that mononuclear cell $\mathrm{GH}$ production was not regulated by the pituitary GH/IGF- 1 axis.

The negative correlations between $\mathrm{GH}$ mRNA and with $\mathrm{ACTH}$ and NEPI suggest that these hormones could be participating in the down regulation of $\mathrm{GH}$ gene expression in PBMCs. Independent influences of $\mathrm{ACTH}$ and NEPI on cellular immune functdon have been reported. An ACTH receptor is expressed on human mononuclear cells (Gilliland et al., 1990) and ACTH can block interferon productdon by murine macrophages and splenocytes (Smith et al., 1987). Similarly catecholamines can alter the lymphocyte subset distribution in the peripheral circulation (Crary et al., 1983; Landmann et al., 1984; Koff and Dunegan, 1985), diminish lymphocyte responsiveness to mitogens by stimulation of intracellular cAMP levels (Crary et al., 1983; Koff and Dunegan, 1985), down-regulate IL-2 receptors (Felten et al., 1987), and increase natural killer cell activity (Hellstrand et al., 1985). Therefore, these observations provide a rationale for further testing of in vitro influence of ACTH and NEPI on mononuclear cell GH mRNA levels.

Of interest was the fact that the cortisol levels did not have a similar relationship. This finding might be explained in part by timing of the sample collection, but this could not explain the ACTH-cortisol dissociation at baseline. It would appear that there is a threshold level required for ACTH changes to be reflected in a rise in cortisol levels (Malarkey et al., 1995).

What is the potential relevance of chronic stress altering GH mRNA levels in mononuclear cells of caregivers? First, GH has been shown to have a significant influence on cellular and humoral immunity (Weigent and Blalock, 1990; Berczi, 1994). For example, GH enhances IL-2 production by lymphocytes (Schimpff and Repellin, 1990), natural killer cell activity in women with impaired $\mathrm{GH}$ secretion (Crist et al., 1987) and superoxide anion generation and bacterial killing (Edwards et al., 1988) by macrophages (Sabharwal et al., 1992b). In addition, recombinant human GH can stimulate B-cell immunoglobulin synthesis and proliferation in serum-free medium (Yoshida et al., 1992). The importance of GH to cellular immunity is further highlighted by the fact that immune organs also express the GH gene. Utilizing an in situ hybridization technique, we have localized GH mRNA to various cell types in each organ of the human immune system, including lymphomas (Wu et al., 1996). In addition, mononuclear cell GH production seems to be involved in lymphocyte proliferation (Weigent et al., 1991).

An intriguing observation was made by Stephenson et. al. (1991) that adding GH to a viral vaccine provided complete protection to infection in a murine encephalitis model. Also, we have recently observed that many caregivers have delayed wound healing (Kiecolt-Glaser et al., 1995) and are unable to develop antibodies or an appropriate cellular immune response to an influenza vaccine, leaving them unprotected against infection (32). It is tempting to speculate that the decreased GH mRNA that we found in the mononuclear cells of these chronically stressed caregivers was partially responsible via defective local GH production for their poor response to influenza vaccine and their delayed wound healing (33).

In summary, we have found that caregiving is associated with a down-regulation of GH mRNA in peripheral blood mononuclear cells. Additionally, increased NEPI levels, and elevated concentrations of $\mathrm{ACTH}$ are correlated with this finding. These observations suggest that the social isolation and other stressful influences associated with caregiving alter the brain's neuroendocrine control of the HPA and SMA axis. These and perhaps other influences are then transmitted to the mononuclear cells where they alter $\mathrm{GH}$ gene expression.

\section{Acknowledgments}

We would like to express our appreciation to Phil Marucha for his helpful suggestions, to Carolyn Cheney for technical expertise, and to the nurses on the General Clinical Research Center for their help in the reactivity protocol. This work was supported in part by NIH grants P01AG1 1585 and General Clinical Research Center grant M01RR00034.

\section{References}

Ader, R., Felten, D. L., and Cohen, N. (1990). In: Psychoneuroimmunology. Academic: New York, pp. 1990.

Berczi, I. (1994). Neuroimmunododulation 1, 201-216.

Berkman, L. F. (1995). Psychosom. Med. 57, 245-254.

Cacioppo, J. T., Malarkey, W. B., Kiecolt-Glaser, J. K., et al. (1995). Psychosom. Med. 57, 154-164.

Crary, B., Hauser, S., and Borysenko M. (1983). J. Immunol. 131, 1178-1181.

Crist, D. M., Peake, G. T., Mackinnon, L. T., Sibbitt, W. L., and Kraner, J. C. (1987). Metabolism 36, 1115-1117.

Edwards, C. K., Ghiasuddin, S. M., Schepper, J. M., Yunger, L. M., and Kelley, K. W. (1988). Science 239, 767-771.

Felten, D. L., Felten, S. Y., Bellinger, D. L., et al. (1987). Immunol. Rev. 100, 225-260.

Gilliland, G. S., Perrin, K., Blanchard, K., and Bunn, H. F. (1990). Proc. Natl. Acad. Sci. USA 87, 2725-2729.

Hattori, N., Ikekubo, K., Ishihara, T., Moridera, K., Hino, M., and Kurahachi, H. (1994). J. Clin. Endocrinol. Metab. 79, 16781680 .

Hellstrand, K., Hermodsson, S., and Strannegard O. (1985). J. Immunol. 134, 4095-5001.

Kiecolt-Glaser, J. K., Glaser, R., Gravenstein, S., Malarkey, W. B., and Sheridan, J. (1996). Proc. Natl. Acad. Sci. USA 93, 3043-3047.

Kiecolt-Glaser, J. K., Malarkey, W. B., Cacioppo, J. T., and Glaser, R. (1990). In: Handbook of Human Stress and Immunity. Academic: New York, pp. 321-339. 
Kiecolt-Glaser, J. K., Marucha, P. T., Malarkey, W. B., Mercado, A. M., and Glaser, R. (1995). Lancet 346, 1194-1196.

Koff, W. C. and Dunegan, M. A. (1985). J. Immunol. 135, 350-354.

Landmann, R. M. A., Muller, F. B., Perini, C. H., et al. (1984). Clin. Exp. Immunol. 58, 127-135.

Malarkey, W. B., Pearl, D. K., Demers, L. M., and Kiecolt-Glaser, J. K., (1995). Psychoneuroendocrinology 20, 499-508.

Pierce, G. F. and Mustoe, T. A. (1995). Annu. Rev. Med. 46, 467-481.

Sabharwal, P., Glaser, R., LaFuse W., et al. (1992). Proc. Natl. Acad. Sci. USA 89, 7713-7716.

Sabharwal, P., Zwilling, B., Glaser, R., and Malarkey, W. B. (1992). Prog. Neuroendocrinimmunology 5, 120-125.

Schimpff, R. M. and Repellin, A. M. (1990). Hormone Res. 33, 171-176.

Sgoutas-Emch, S. A., Cacioppo, J. T., Uchino B. N., et al. (1994). Psychophysiology 31, 264-273.

Siebert, P. D. and Larrick, J. W. (1993). BioTechniques 14, 244-249.

Smith, E. M., Brosnan, P., and Meyer, W. J. (1987). N. Eng. J. Med. 317, 1266-1269.
Stephenson, J. R., Lee, J. M., Bailey, N. Shepherd, A. G., and Melling, J. (1991). J. Infect. Dis. 164, 188-191.

Varma, S., Sabharwal, P., Sheridan, J. F., and Malarkey, W. B. (1993). J. Clin. Endocrinol. Metab. 76, 49-53.

Wang, A. M., Doyle, M. V., and Mark, D. F. (1989). Proc. Natl. Acad. Sci. USA 86, 9717-9721.

Wang, D., You, L., Sneddon, J., Cheng, S. J., Jamasbi, R., and Stoner, G. D. (1995). Mol. Carcinogenesis 14, 84-93.

Weigent, D. A. and Blalock, J. E. (1990). Prog. Neuroendocrinimmunology 3, 231-241.

Weigent, D. A., Blalock, J. E., and LeBoeuf, R. D. (1991). Endocrinology 128, 2053-2057.

Wu, H., Devi, R., and Malarkey W. B. (1995). Endocrinology 137, 349-353.

Wu, H., Devi, R., and Malarkey, W. B. (1996). J. Clin. Endocrinol. Metab. 81, 1278-1282.

Yoshida, A., Ishioka, C., Kimata, H., and Mikawa, H. (1992). Acta Endocrinol. 126, 524-529. 